Hidden Caliphate 



\title{
HIDDEN CALIPHATE
}

Sufi Saints beyond the Oxus and Indus

\author{
WALEED ZIAD
}

HARVARD UNIVERSITY PRESS

Cambridge, Massachusetts o London, England 
Copyright $(9$ 202I by the President and Fellows of Harvard College All rights reserved

Printed in the United States of America

$$
\begin{aligned}
& \text { First printing } \\
& \text { Design: Graciela Galup } \\
& \text { Cover art: Getty Images } \\
& 9780674269378 \text { (EPUB) } \\
& 9780674269385 \text { (PDF) }
\end{aligned}
$$

The Library of Congress Cataloged the printed edition as follows:

Names: Ziad, Waleed, I980- author.

Title: Hidden caliphate : Sufi saints beyond the Oxus and Indus /

$$
\text { Waleed Ziad. }
$$

Description: Cambridge, Massachusetts : Harvard University Press, 202 I. I Includes bibliographical references and index.

Identifiers: LCCN 202IOI 2943 I ISBN 97806742488 I 6 (cloth)

Subjects: LCSH: Muslim saints-Asia, Central-History. I Muslim saints-Asia, Central-Biography. I Muslim saints-Pakistan-History. I

Muslim saints-Pakistan-Biography. I Sufism-Political aspects—History. I Caliphate—History. I Islam and politics—History. I Da'wah (Islam)-History.

Classification: LCC BPI89.4 .Z53 202I I DDC 297.6/10958-dc23

LC record available at https://lccn.loc.gov/202 IOI 2943 
For my family 
